Article

\title{
Applying a Comprehensive Action Determination Model to Examine the Recycling Behavior of Taipei City Residents
}

\author{
Wei-Ta Fang ${ }^{1} \mathbb{D}$, Mei-Hsuan Huang ${ }^{2,3, *}$, Bai-You Cheng ${ }^{4} \mathbb{D}$, Rong-Jeo Chiu ${ }^{3}$, Yi-Te Chiang ${ }^{1} \mathbb{D}$, Chun-Wei Hsu $^{1}$ \\ and Eric $\mathrm{Ng}^{5, *(\mathbb{D})}$
}

1 Graduate Institute of Environmental Education, National Taiwan Normal University, Taipei 11677, Taiwan; wtfang@ntnu.edu.tw (W.-T.F.); faratajiang@gmail.com (Y.-T.C.); s1013202@gmail.com (C.-W.H.)

2 Center for General Education, National Taiwan Normal University, Taipei 10610, Taiwan

3 Graduate Institute of National Development, National Taiwan University, Taipei 10617, Taiwan; hakkachiu888@gmail.com

4 Graduate Institute of Environmental Resources Management, TransWorld University, Douliu City 64063, Yunlin County, Taiwan; biyocheng@twu.edu.tw

5 School of Management and Enterprise, University of Southern Queensland, Toowoomba, QLD 4350, Australia

* Correspondence: t24007@ntnu.edu.tw (M.-H.H.); eric.ng@usq.edu.au (E.N.); Tel.: +886-2-77491125 (M.-H.H.); +61-7-4631-1298 (E.N.)

check for

updates

Citation: Fang, W.-T.; Huang, M.-H.; Cheng, B.-Y.; Chiu, R.-J.; Chiang, Y.-T.; Hsu, C.-W.; Ng, E. Applying a

Comprehensive Action

Determination Model to Examine the Recycling Behavior of Taipei City Residents. Sustainability 2021, 13, 490 https://doi.org/10.3390/su13020490

Received: 26 November 2020

Accepted: 1 January 2021

Published: 6 January 2021

Publisher's Note: MDPI stays neutral with regard to jurisdictional clai$\mathrm{ms}$ in published maps and institutional affiliations.

Copyright: $\odot 2021$ by the authors. Licensee MDPI, Basel, Switzerland. This article is an open access article distributed under the terms and conditions of the Creative Commons Attribution (CC BY) license (https:// creativecommons.org/licenses/by/ $4.0 /)$.

\begin{abstract}
With the occurrence of rapid global economic growth concerns about waste and its related effects on the environment are on the rise. There has been an increasing focus towards sustainable development and waste recycling as part of environmental sustainability strategies, and the encouraging of recycling behavior has received considerable attention from various environmental stakeholders. While numerous studies have used grounded theories such as the theory of planned behaviors and the norm activation model to examine environmental behaviors, a lack of consideration of other important variables in these studies has been revealed. This study aimed to address this gap by adopting the comprehensive action determination model, which comprises a wider group of influencing variables related to norms, intentions, situations, and habits. This model was tested using structural equation modelling with a sample of 386 valid questionnaires collected from Taipei City residents in the domain of recycling behaviors. Results indicated that awareness had a positive influence on personal norms towards recycling behaviors; social norms had a positive influence on personal norms towards recycling behaviors; attitudes had a positive influence on recycling intentions; social norms had a positive influence on recycling intentions; personal norms had a positive influence on recycling intentions; perceived behavior control had a positive influence on recycling intentions; recycling intentions had a positive influence on recycling behavior; and recycling habits had a positive influence on recycling behavior. However, findings did not support the positive impact of perceived behavioral control on recycling behavior.
\end{abstract}

Keywords: comprehensive action determination model; recycling behavior; resource recovery; structural equation modeling; Taipei City

\section{Introduction}

While the rapid global economic growth in recent years has led to many advance developments and benefits, it has also given rise to increasing concerns about waste and its related effects on the environment. As sustainable development becomes a major trend for international environmental protection, waste recycling as part of an environmental sustainability strategy has received considerable attention from various environmental stakeholders such as international organizations, government agencies, businesses, communities, and researchers in an attempt to encourage, promote, and facilitate recycling behavior. Although many prior studies have been conducted using a number of different approaches/models (mainly normative activation model, theory of planned behavior) to 
examine people's pro-environmental behaviors (including recycling behavior), none of the approaches/models by themselves have offered an adequate representation of the multiple determining factors of pro-environmental behaviors.

Ajzen's theory of planned behavior (TPB) is regarded as one of the most commonly used theories by researchers to interpret and predict different pro-environmental behaviors $[1,2]$. According to the theory of planned behavior, there are three key elements that influence behavioral intentions which can directly predict the behavior of individuals' actions. These elements are: (1) an individual's attitude towards a particular behavior; (2) perceived behavioral control in which an individual has the ability to control the external environment; and (3) social norms that refer to an individual's perceptions of external social pressures to act in a certain way [3,4]. While the theory of planned behavior emphasizes the importance of behavioral intentions, it fails to acknowledge the impact of personal norms, habits, and situational circumstances. In the domain of pro-environmental behaviors, the theory of planned behavior has been effective in explaining recycling behaviors $[5,6]$, the use of public transportation [7], energy conservation [8], food consumption decisions [9], and the purchase of green products [10].

Another theory often used to predict pro-environmental behaviors is the norm activation model (NAM), which was first proposed by Schwartz [11]. The norm activation model posits that prosocial behavior is likely to derive from personal norms in which altruistic behaviors are displayed through a feeling of moral obligation [11,12]. There are three key factors in the norm activation model used to predict pro-environmental behaviors. Firstly, awareness of need which indicates an individual being aware of and perceiving that someone or something is in need. Secondly, ascription of responsibility that reflects an individual's personal feeling towards being responsible for the consequences of his/her behavior [13]. Thirdly, awareness of consequences that refers to an individual's perception about the impact that his/her own behavior has on others [13]. The norm activation model considers personal norms to be the most influential predictor of norm-oriented behavior but has neglected other non-moral variables such as social norms, habits, behavioral intentions, perceived behavioral control, and situational circumstances. Previous studies have adopted the norm activation model to investigate different domains of environmentalism, such as participation in green consumption activities $[7,11]$, recycling behaviors $[12,14]$, use of green transport [15], environmental pollution [16], and energy conservation [17].

In view of these limitations and the complexity of examining pro-environmental behaviors, Klöckner and Blöbaum [18] proposed a complex comprehensive action determination model (CADM), which has been developed by integrating the theory of planned behavior, the norm activation model, and other variables such as habits and situational influence into a behavioral decision model with the aim to provide a sounder explanation towards pro-environmental behaviors. Their study has used the comprehensive action determination model to explore the correlation between variables related to recycling behaviors including awareness, personal norms, social norms, perceived behavioral control, intention to recycle, recycling habits, and recycling attitudes, to gain a better understanding about the path analysis on recycling behaviors [18]. The results indicate that the most important psychological variables of recycling behavior are behavioral intention, perceived behavioral control, personal norms, social norms, and habits, and pointed out that understanding the patterns of human behavior is an important factor in the development of effective recycling policies. Although some studies that adopted the comprehensive action determination model have indicated the applicability of this model to a variety of situations and behaviors, limited evidences have prompted the need for further studies to be conducted in order to gain greater insights into this model where more conclusive findings can be added to the extant literature. Thus, this study seeks to investigate recycling behaviors using the comprehensive action determination model, and specifically in the Taiwan urban context.

Taipei City is the national capital of Taiwan. Industry and commerce have flourished rapidly, and a large number of people have lived in the Taipei metropolitan area since 
the 1950s. The dense population has not only increased environmental loads but also caused great environmental pollution and destruction. As a result, the rapid growth in population has caused an ever-expanding natural destruction, coupled with the evershrinking human living space, and the living environment is deteriorating day by day, resulting in increasing environmental pollution and environmental loads. Environmental pollution does not only affect human health but also affects human development. Among them, the ever-increasing waste is one of the several critical environmental problems that Taipei City addressed in the 1960s. Taipei City's garbage collection and disposal policy aims to "reduce the source of waste and accelerate recycling" in line with the perspective of resource sustainability, advocating effective resource recycling methods to recycle resources efficiently and gradually achieve the goal of recycling all the garbage and dumping zero waste. Since 2000, the Taipei City government has put in place policies that impose garbagebag fees as well as mandate the use of specific environmentally friendly garbage bags. According to the Department of Environmental Protection in Taipei City, the resource recovery rate has improved significantly from $5.88 \%(1.11 \mathrm{~kg} /$ day $)$ in 1998 , to $55.23 \%$ $(0.37 \mathrm{~kg} /$ day) in 2015 [19].

Generally, Taipei City residents are expected to take their garbage wrapped in specific bags and wait for the arrival of the garbage truck at a designated place during a scheduled time of the day. They will also carry out garbage classification and resource recycling in accordance with the regulations stipulated by the local authority from the Taipei City. The recycling content includes wastepaper, plastic bags, Styrofoam, bottles and cans, paper containers, household appliances, computers, screens, keyboards, waste plastics, waste tires, light tubes, batteries, waste oil, kitchen waste, and so on. Although Taipei City residents have busy lifestyles, they do spend time sorting their waste materials according to specific requirements and hand them to the recycling staff from the Department of Environmental Protection at the designated garbage and resource recovery pick-up points.

Therefore, the key purpose of this research is to use the comprehensive action determination model to examine the recycling behaviors of Taipei City residents. Specifically, to better understand their motives and intentions towards recycling behaviors, the key variables affecting recycling behaviors, and the causal relationship between these variables.

\section{Theories and Hypotheses}

This study has adopted the comprehensive action determination model to explore the correlations between the variables towards recycling behaviors. Based on the extant literature, the following hypotheses will be examined using the proposed research framework as presented.

\subsection{Awareness and Personal Norms}

Using the norm activation model in their studies, Eriksson et al. [16] suggest that problem awareness and personal norms have a positive impact on the willingness to reduce environmental pollution, while Mainieri et al. [14] reveal that individuals with higher awareness of consequences are more morally responsible and have higher willingness to participate in green consumption activities. Hopper and Nielsen [20] further explained, with the use of norm activation model, that when social norms are accepted by people personal norms will be activated and therefore the ascription of responsibility and awareness of consequences in turn will influence and ultimately produce behaviors. Furthermore, other previous studies e.g., $[11,21,22]$ have indicated the influence of awareness on personal norms in different contexts. Therefore, in order to understand the effect of awareness on personal norms towards the recycling behaviors of Taipei City residents, the first proposed hypothesis is:

Hypothesis 1 (H1). Awareness (AW) has a positive impact on personal norms (PN) towards recycling behaviors. 


\subsection{Social Norms and Personal Norms}

A study by Bamberg et al. [21] shows that social norms have a positive impact on personal norms, and personal norms have a positive effect on people's intentions to use public transportation. In addition, social norms also indirectly influence the behavioral intention mediated by guilt. Cialdini et al. [22] state that social norms are widely used to explain most human behaviors. Social norms obviously have a considerable influence on behavior, but this influence has a prerequisite. In other words, it is a kind of descriptive norm or injunctive norm that can correctly predict the possibility of actions in concert. Secondly, various issues such as personal attention, cultural differences, and behavioral context must be considered as they have different influences on behavior prediction. On the contrary, a study by Stok [23] suggests that social norms can have short-term negative effects on personal norms in terms of actual fruit consumption. Although prior studies have supported the positive impact of social norms on personal norms, they are generally based on the normative activation model and the theory of planned behavior. In contrast, this study has adopted the comprehensive action determination model, which is used by limited studies $[18,24,25]$, to investigate the impact of social norms on personal norms towards the recycling intention of Taipei City residents. Given that a different model (i.e., the comprehensive action determination model) is used and the differing contexts (e.g., cultural, recycling behavior of urban Taipei City residents), it is useful to examine if a similar positive effect of social norms on personal norms exists. Thus, the second hypothesis proposed is:

Hypothesis 2 (H2). Social norms have a positive influence on personal norms towards recycling behaviors.

\subsection{Attitudes and Recycling Intentions}

Fishbein and Ajzen [26] in his proposed theory of reasoned action suggest that actions can be completely controlled by individual behaviors, and that the most direct determinant of a particular behavior by an individual is "behavioral intention", and behavioral intentions will be affected by "attitudes" and "social norms". Ajzen [3] extends the theory of reasoned action by adding a new variable to this model, which is "perceived behavioral control". Perceived behavioral control refers to the actor's perception of his/her ability, knowledge, endurance, and time to exercise. Similar to a "concept of self-efficacy", it is regarded as a belief in one's own ability to organize target behavior [27]. The theory of planned behavior claims that the more positive an individual's attitude to the behavior is, the more the social norms support the individual to engage in the behavior. Thus, the third hypothesis proposed is:

Hypothesis 3 (H3). Attitudes (AT) have a positive impact on recycling intentions (IN).

\subsection{Social Norms and Recycling Intentions}

Armitage and Conner [28] integrated a total of 185 research data sets on planned behaviors in 1997, and argue that the social norms in the theory of planned behavior are incomplete and rarely succeed in predicting behavior intentions. Most of the reasons are attributed to the unsound measurement tools and the need to expand the measurement range. Social norms can also be used as social pressure to influence an individual to follow others, but social pressure is rarely so direct or clear. The behavior of most people seems likely to be unaffected by social pressure. Cialdini, Reno and Kallgren [22] mention that the term norm is only used for ideal behaviors (or prohibited behaviors) and it relates to how people perceive normal behaviors. "Normal" behaviors are usually called descriptive norms, explaining that we comply with descriptive norms. Social norms are divided into descriptive norms and injunctive norms. When we perform the same actions based on what other people are doing, such as carrying reusable shopping bags when shopping, it can be regarded as a descriptive norm. On the other hand, the injunctive norms are those that are 
approved or disapproved by others. They are mandatory and punitive and apply to most people. For example, in some countries, it is stipulated that car drivers should drive on the right, and drivers must comply with this regulation. This is an injunctive norm. The key difference between the two types of norm is that the injunctive norms are often punitive [29]. A study by Doran and Larsen [30] show that social and personal norms are very important in explaining the intention of choosing ecotourism. Nigbur et al. [31] argue that injunctive norms and descriptive norms can be used to predict personal norms mediated by recycling behaviors and explain recycling intentions and behaviors. While studies by Park and $\mathrm{Ha}$ [32], and Bratt [33] reveal that social norms are not directly related to intentions and behavior, these results seem to be contradictory to other scholars [34-36] who have found that social norms affected environmental behavior when comparing different groups of participants in their studies. Therefore, this study seeks to better understand the role that social norms play in the recycling behaviors of Taipei City residents. Given the above, a fourth hypothesis is proposed:

Hypothesis 4 (H4). Social norms (SN) have a positive impact on recycling intentions (IN).

\subsection{Personal Norms and Recycling Intentions}

Thøgersen [12] proposed the classification of norms. For example, Cialdini et al. [22] categorize norms into descriptive norms and injunctive norms, and subdivided them into social norms, personal norms, introjected norms, and integrated norms. Introjected norms mean that behavioral norms are controlled by external rewards and punishments, and norms are internalized on the surface. Integrated norms mean that the moral norms are more deeply internalized through reflection and evaluation. The closer a behavior is to the former, the more easily it will be externally affected, and the closer it is to the latter, the more internalized it is. The closer the two norms are, the higher the correlation between them. For example, the correlation between descriptive norms and social norms is higher than that between descriptive norms and introjected norms. Bratt [33] suggests that consumer recycling behavior is based on three variables: environmental belief, social norms, and personal norms. The research results show that social norms are not directly correlated with environmental recycling behaviors, but they are indirectly correlated with each other mediated by personal norms. This verified the findings by Hopper and Nielsen [20], and Harland et al. [29] whereby the inclusion of personal norms in the theory of planned behavior can better explain various intentions and behavior areas. In combining eight social and environmental psychological variables in environmental behavior models including the norm activation model, the theory of planned behavior, and pro-environmental behaviors, Bamberg and Möser [37] agree that besides attitudes and perceived behavioral control, personal norms have a direct effect on behavioral intentions. Thus, the next hypothesis proposed is:

Hypothesis 5 (H5). Personal norms (PN) have a positive impact on recycling intentions (IN).

\subsection{Perceived Behavioral Control and Recycling Intentions}

Ajzen [3] refers to perceived behavioral control as the degree to which an individual recognizes the difficulty of engaging in a certain behavior. When an individual recognizes that he/she may have more opportunities and resources, or the barriers and difficulties he/she expects to encounter will be lesser, his/her perceived behavior control over induced behaviors will be stronger, and vice versa. Perceived behavioral control can be divided into external control and internal control. Internal control is individual behavior, such as personal shortcomings, skills, abilities, or emotions. External control factors include information, opportunity, dependence on others, etc. [38]. Chan and Bishop [34] indicate that there is a correlation between moral norms and recycling, and subsequently concluded that moral norms can replace the recycling attitude applied in the theory of planned behavior. Moral norms, social norms, and perceived behavioral control are predictors of 
recycling intentions whereas perceived behavioral control has both a direct and indirect effects on recycling intentions. Therefore, the sixth hypothesis proposed is:

Hypothesis 6 (H6). Perceived behavioral control (PBC) has a positive impact on recycling intentions (IN).

\subsection{Perceived behavioral Control and Recycling Behaviors}

Mahmud and Osman [39] have used the theory of planned behavior to investigate the recycling intentions and behaviors of secondary school students in Malaysia, including confirmatory factor analysis and structural equation modeling. The results show that perceived behavioral control is the strongest predictor of intention behaviors whereas social norms have a similar effect but to a lesser extent. A study by Ioannou et al. [35] about the recycling behaviors in Athens, Greece shows that attitude and perceived behavioral control in the theory of planned behavior are key explanatory factors. However, when Kaiser and Gutscher [40] further examined the recycling behaviors of Swiss residents using structural equation modeling they revealed that while the variables in the theory of planned behavior positively affect the various pro-environmental behaviors, the perceived behavioral control has a relatively weak influence on some pro-environmental behaviors. Thus, the next proposed hypothesis is:

Hypothesis 7 (H7). Perceived behavioral control (PBC) has a positive impact on recycling behaviors $(B H)$.

\subsection{Recycling Intentions and Recycling Behaviors}

Fishbein and Ajzen [26] have proposed that "behavioral intention" is a necessary process for behavior performance, a decision before the behavior appears, and the degree of inclination that an individual has to engage in behaviors. Intention is the degree to which an individual wants to engage in a certain behavior positively or negatively. Therefore, it can be categorized into favorable and unfavorable behavioral intention. Bearden and Woodside indicate that the degree of an individual's tendency to engage in a certain behavior can be measured by the individual's willingness to try and the level of effort put into engaging in the behavior. Taylor and Todd [41] have undertaken analysis with structural equation modeling to explore the factors that drive people to use online business networking, with the results suggesting that social norms indirectly affect online behaviors through the mediation of attitudes and behavioral intentions. Perugini and Bagozzi [42] have further added the mediator variable "desire" to the theory of planned behavior framework, to investigate the effort expended in studying of a total of 122 students at the University of Rome. As such, the eighth hypothesis is proposed:

Hypothesis 8 (H8). Recycling intentions (IN) have a positive impact on recycling behaviors (BH).

\subsection{Recycling Habits and Recycling Behaviors}

Verplanken and Aarts [43] refer habit as a behavior pattern acquired by frequent repetition or physiologic exposure that shows itself in regularity or increased facility of performance. However, it is worth noting that not all repetitive behaviors will eventually become habits since the development of habits depends on the catalysts and prompt reflection of the goal of behavior. For example, in order to attend class on time (target catalyst), someone arrives at the bus station at 8 o'clock every day (prompt response). Therefore, daily reminders and repeated operations enable a person to develop a habit [44]. If a behavior is habitual, the influence of psychological variables such as personal norms and/or behavior intentions will be insignificant because it has become almost involuntary. Cheung et al. [5] have used the theory of planned behavior to investigate the recycling behaviors of college students and reveal that past behaviors have an impact on recycling behaviors. A study by Carrus et al. [7] to investigate the use of public transportation and household garbage collection behavior suggests that there is a direct correlation between 
past behavior and intention, and the frequency of past behavior has a positive correlation with the intention. Ittiravivongs' study [6] of Thai households reveals that recycling behaviors may not be related to recycling intentions and recycling facilities, but instead argues that recycling habits are more closely correlated to household recycling behaviors. Tonglet et al. [45] has adopted the theory of planned behavior to explore a roadside recycling program and the results suggest that past recycling experiences, attention to the community, and the consequences of recycling are also important predictors of recycling behaviors. Therefore, the final hypothesis proposed is:

Hypothesis 9 (H9). Recycling habits (HA) have a positive impact on recycling behaviors (BH).

Given the above proposed hypotheses, a research framework is developed for this study as shown in Figure 1 below.

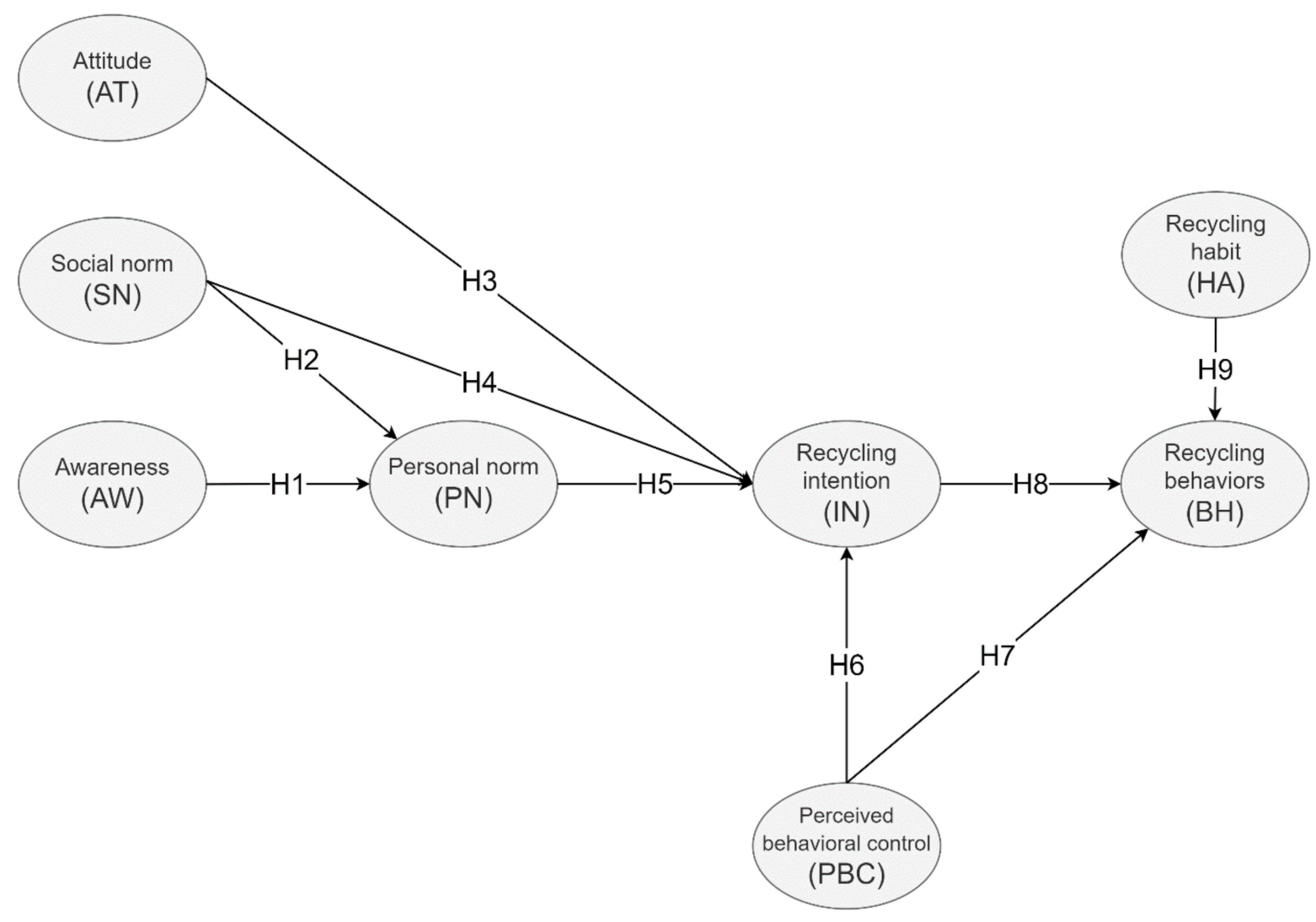

Figure 1. Research framework of this study.

\section{Materials and Methods}

\subsection{Respondents and Data Collection}

In this study, the sample consisted of adult residents living in Taipei City, in which there were a total of 2,331,156 residents aged 20 or older according to the demographic statistics of the administrative districts of Taipei City compiled by the Department of Civil Affairs in 2016. A "stratified proportional sampling" method was used to determine the proportion of each administrative district in the population, and the number of people that must be drawn from each administrative district. This was then followed by the cluster sampling technique, using non-probability purposive sampling based on the population sizes of the 12 districts in Taipei City. Lodico et al. [46] have indicated that if the number of individuals within a population is 5000 or more, the sample size must be between 350 and 500. In this study, the sampling ratio is set to 0.5 , the sampling error is $<0.05$, and the reliability is set to $95 \%$ [47]. A total of 400 questionnaires were distributed for 
self-completion, of which 386 were completed and analyzed accordingly. There were 14 questionnaires deemed to be invalid and these have not been included in the final analysis.

According to the National Taiwan Normal University Research Ethics Committee, our research is not considered within the scope of the Human Subjects Research Act. Thus, the committee approved the study protocol (201912HS001) and agreed that an informed consent was obtained when respondents complete the questionnaire, which clearly outlined the research purpose and content. All data collected was handled with strict confidentiality and respondents remained anonymous and could not be identified.

\subsection{Questionnaire Design}

The questionnaire designed for this study has been divided into two main sections. The first section was related to the demographic profiles, whereas the second section was based on the eight key variables as outlined in the proposed research framework; namely "awareness", "social norms", "personal norms", "perceived behavioral control", "attitudes", "recycling behavior intentions", "recycling habits", and "recycling behaviors". A total of 19 questions related to these eight key variables were adapted from the respective literature. There were two questions related to the awareness variable, and they were aligned with those posed by scholars such as Klöckner and Blöbaum [18], Klöckner and Oppedal [24], Ofstad et al. [25], and Klöckner and Matthies [48]. In terms of the social norms variable, two questions were developed based on studies by Klöckner and Blöbaum [18], Klöckner and Oppedal [24], Ofstad et al. [25], and Klöckner and Matthies [48]. Two personal norms-related questions that were sourced from Klöckner and Blöbaum [18], Ofstad et al. [25], and Tonglet et al. [45] were included. With regards to the perceived behavioral control variable, two related questions were included that were aligned to those presented by Klöckner and Blöbaum [18], Klöckner and Oppedal [24], Ofstad et al. [25], Tonglet et al. [45], and Klöckner and Matthies [48]. Based on studies from Klöckner and Blöbaum [18], Klöckner and Oppedal [24], Ofstad et al. [25], Klöckner and Matthies [48], and Ramayah et al. [49], two related questions were developed about the attitude variable. The two questions related to the recycling behavior intention variable were supported by Klöckner and Blöbaum [18], Klöckner and Oppedal [24], Ofstad et al. [25], Klöckner and Matthies [48], and Minton and Rose [50]. As for the recycling habits variable, there were three questions included that aligned with those proposed by Ofstad et al. [25], and Verplanken and Orbell [38]. Regarding the final variable on recycling behaviors, four related questions were developed, and they were supported by Klöckner and Blöbaum [18], Klöckner and Oppedal [24], and Ofstad et al. [25].

\subsection{Validity and Reliability of the Questionnaire}

The Statistical Package for the Social Sciences (SPSS) software program was used to conduct the analysis. The frequency analysis was used to calculate the total number of occurrences, the mean and standard deviation (SD) scores for the demographic questions, and items in the eight key variables (i.e., awareness, social norms, personal norms, perceived behavioral control, attitudes, recycling behavior intentions, recycling habits, and recycling behaviors). As for the Pearson correlation technique, it was used to measure the strength and direction of the relationship that exists between these key variables. Finally, multiple regression analysis was used to predict the influence of awareness, social norms, personal norms, perceived behavioral control, attitudes, recycling behavior intentions, and recycling habits. A five-point Likert scale (i.e., $1=$ "Strongly disagree" to $5=$ "Strongly agree") was also used for the measurement in this study. The questionnaire was initially reviewed by three experts in related fields, where some minor revisions were made to the semantic meaning and some wordings were simplified to ensure more colloquial and clear terms were used to enable the respondents to understand questions in the local context. The revised questionnaire was subsequently pre-tested by 163 individuals, where all variables (except social norms which indicated moderate reliability) showed high reliability with 
a Cronbach's $\alpha$ value higher than 0.7 [51]. The Cronbach's $\alpha$ values for the respective variables were: awareness $(0.825)$, social norms $(0.678)$, personal norms $(0.852)$, perceived behavioral control (0.854), attitudes (0.888), recycling behavior intentions $(0.894)$, recycling habits (0.922), and recycling behaviors (0.844).

\section{Results}

\subsection{Descriptive Statistics}

With the 386 valid questionnaires collected, the results showed that there were 216 males (56\%) and 170 females (44\%). Among the respondents, $242(62.7 \%)$ had a college/university degree, and this was followed by $109(28.2 \%)$ with a master's degree. Twenty-six (6.7\%) graduated from general and vocational high school, five graduated from junior high and below $(1.3 \%)$, and the remaining four had a doctorate degree $(1 \%)$. In terms of household garbage disposal and resource recycling methods, $229(59.3 \%)$ of them waited for and placed household garbage in garbage trucks at designated hours and locations, $114(37.3 \%)$ put household garbage at a designated room in their apartment building, and $13(3.4 \%)$ disposed household garbage by other methods.

As shown in Table 1, findings for the items related to awareness indicated an overall awareness mean score of 3.99. Among the two awareness-related items "I feel I am responsible for the problems caused by whether the waste is sorted at home" had a higher mean score than "I feel I am responsible for the environmental problems caused by the fact that the waste is not sorted". The results revealed an internal consistency of high reliability measurements with a Cronbach's value of 0.819 for the awareness-related items.

Table 1. Descriptive statistics for awareness items.

\begin{tabular}{ccc}
\hline Awareness & Mean & SD \\
\hline AW1 I feel I am responsible for the problems caused by whether the waste is sorted at home. & 4.02 & 1.013 \\
\hline AW2 I feel I am responsible for the environmental problems caused by the fact that the waste is not sorted. & 3.96 & 1.004 \\
\hline Overall awareness & 3.99 & 0.927 \\
\hline
\end{tabular}

The results from Table 2 showed that the overall mean score for the social norms related items was 3.85. There were two items in the social norms variable, both "Persons (family members, colleagues, and friends) who are important to me would influence me to sort household waste" and "I think people (family members, colleagues, and friends) around me who are important to me would expect me to do waste sorting at home" had a very similar mean score of 3.85 and 3.84 respectively. The Cronbach's value of 0.675 suggested a moderate level of internal consistency reliability measurements for the social norms-related items.

Table 2. Descriptive statistics for social norms items.

\begin{tabular}{|c|c|c|}
\hline Social Norms & Mean & SD \\
\hline $\begin{array}{l}\text { SN1 I think people (family members, colleagues, and friends) around me who are important to me would } \\
\text { expect me to do waste sorting at home. }\end{array}$ & 3.84 & 0.950 \\
\hline $\begin{array}{c}\text { SN2 Persons (family members, colleagues, and friends) who are important to me would influence me to } \\
\text { sort household waste. }\end{array}$ & 3.85 & 0.884 \\
\hline Overall social norms & 3.85 & 0.796 \\
\hline
\end{tabular}

Findings (Table 3) of the personal norms-related item revealed an overall mean score of 4.29. There were two items related to personal norms, and "In my opinion, everyone should have the responsibility of household waste sorting and recycling" had a higher mean score than "In my opinion, it is wrong not to do household waste sorting and recycling". The Cronbach's $\alpha$ value of 0.762 indicated a high level of internal consistency reliability measurements for the personal norms items. 
Table 3. Descriptive statistics for personal norms items.

\begin{tabular}{ccc}
\hline Personal Norms & Mean & SD \\
\hline PN1 In my opinion, it is wrong not to do household waste sorting and recycling. & 4.25 & 0.815 \\
\hline PN2 In my opinion, everyone should have the responsibility of household waste sorting and recycling. & 4.34 & 0.732 \\
\hline Overall personal norms & 4.29 & 0.696 \\
\hline
\end{tabular}

As outlined in Table 4, the findings suggested that the overall mean score for the perceived behavioral control items was 4.33. The two items related to perceived behavioral control were "I know how to do a good job in household waste recycling" and "I know which household waste can be recycled", in which the former had a higher mean score than the latter. The internal consistency of reliability measurements for the perceived behavioral control-related items was considered high, with a Cronbach's value of 0.810 .

Table 4. Descriptive statistics for perceived behavioral control items.

\begin{tabular}{ccc}
\hline Perceived Behavioral Control & Mean & SD \\
\hline PBC1 I know which household waste can be recycled. & 4.30 & 0.649 \\
\hline PBC2 I know how to do a good job in household waste recycling. & 4.36 & 0.596 \\
\hline Overall perceived behavioral control & 4.33 & 0.572 \\
\hline
\end{tabular}

Results for the attitude-related items in Table 5 showed an overall mean score of 4.43 . There were two items related to attitude, of which "I think doing a good job in household waste recycling and sorting will reduce environmental pollution" had a higher mean score than "I think doing a good job in household waste recycling and sorting will help preserve natural resources". The Cronbach's value of 0.829 indicated an internal consistency of high reliability measurements for the attitude-related items.

Table 5. Descriptive statistics for attitude items.

\begin{tabular}{crc}
\hline Attitudes & Mean & SD \\
\hline AT1 I think doing a good job in household waste recycling and sorting will reduce environmental pollution. & 4.47 & 0.661 \\
\hline AT2 I think doing a good job in household waste recycling and sorting will help preserve natural resources. & 4.39 & 0.735 \\
\hline Overall attitudes & 4.43 & 0.646 \\
\hline
\end{tabular}

As presented in Table 6, the overall mean score for the recycling intention items was 4.22. There were two items related to recycling intentions, whereby "I will make a good job of sorting and recycling household waste, rather than disposing of it at will" had a higher mean score than "I plan to make a good job of sorting waste at home in the next 7 days". The Cronbach's $\alpha$ value was 0.706 , which represented a high level of internal consistency of reliability measurements for the recycling intention-related items.

Table 6. Descriptive statistics for recycling intention items.

\begin{tabular}{ccc}
\hline Recycling Intentions & Mean & SD \\
\hline IN1 I plan to make a good job of sorting waste at home in the next 7 days. & 4.15 & 0.889 \\
\hline IN2 I will make a good job of sorting and recycling household waste, rather than disposing of it at will. & 4.30 & 0.763 \\
\hline Overall recycling intentions & 4.22 & 0.728 \\
\hline
\end{tabular}

Findings from Table 7 revealed that the overall mean score for the recycling habits items was 4.29. There were three items about recycling habits, of which "Doing a good job 
of waste recycling and sorting at home is something I would do naturally" had the highest mean score. This was followed by "I unknowingly have already sorted waste at home" and "I do a good job of waste sorting and recycling at home without consideration" The internal consistency reliability for the recycling habits related items was regarded as high and this was evident by the Cronbach's $\alpha$ value of 0.884 .

Table 7. Descriptive statistics for recycling habit items.

\begin{tabular}{ccc}
\hline Recycling Habits & Mean & SD \\
\hline HA1 Doing a good job of waste recycling and sorting at home is something I would do naturally. & 4.39 & 0.738 \\
\hline HA2 I unknowingly have already sorted waste at home. & 4.24 & 0.785 \\
\hline HA3 I do a good job of waste sorting and recycling at home without consideration. & 4.24 & 0.784 \\
\hline Overall recycling habits & 4.29 & 0.707 \\
\hline
\end{tabular}

The overall mean score (as shown in Table 8) for the recycling behaviors items was 4.31. There were four recycling behaviors related items: "I sort and recycle glass waste (wine bottles, glass bottles, etc.) at home", and "I sort and recycle scrap iron (iron bowls, iron pots, keys, etc.) at home" received the highest and lowest mean scores respectively. Other items included: "I sort and recycle scrap aluminum (aluminum cans, aluminum pots, or aluminum basins, etc.) at home" and "I sort and recycle aluminum foil packages (cosmetics, beverage aluminum foil packages, etc.) at home". The Cronbach's value of 0.832 suggested a high level of internal consistency for the recycling behavior-related items.

Table 8. Descriptive statistics for recycling behavior items.

\begin{tabular}{ccc}
\hline Recycling Behaviors & Mean & SD \\
\hline BH1 I sort and recycle scrap iron (iron bowls, iron pots, keys, etc.) at home. & 4.18 & 0.956 \\
\hline BH2 I sort and recycle scrap aluminum (aluminum cans, aluminum pots, or aluminum basins, etc.) at home. & 4.34 & 0.844 \\
\hline BH3 I sort and recycle glass waste (wine bottles, glass bottles, etc.) at home. & 4.40 & 0.797 \\
\hline BH4 I sort and recycle aluminum foil packages (cosmetics, beverage aluminum foil packages, etc.) at home. & 4.32 & 0.832 \\
\hline Overall recycling behaviors & 4.31 & 0.701 \\
\hline
\end{tabular}

Findings from the correlation analysis (see Table 9) revealed that the relationship between behavioral intentions and recycling habits $(r=0.656, p<0.001)$ was the strongest. Results also showed that the Pearson correlation coefficients between the eight variables were in the range of 0.288 to 0.656 . The analysis concluded that all eight variables in this study were correlated and had existing inter-relationships in their paths towards recycling behaviors.

Table 9. Pearson's correlation matrix for each dimension of this study.

\begin{tabular}{cccccccc}
\hline & AW & SN & PN & PBC & AT & IN & HA \\
\hline AW & 1 & & & & & & \\
SN & $0.342^{* * *}$ & 1 & & & & & \\
PN & $0.493^{* * *}$ & $0.326^{* * *}$ & 1 & & & & \\
PBC & $0.387^{* * *}$ & $0.378^{* * *}$ & $0.504^{* * *}$ & 1 & & & \\
AT & $0.426^{* * *}$ & $0.288^{* * *}$ & $0.587^{* * *}$ & $0.498^{* * *}$ & 1 & & 1 \\
IN & $0.455^{* * *}$ & $0.412^{* * *}$ & $0.586^{* * *}$ & $0.539^{* * *}$ & $0.513^{* * *}$ & 1 & $0.518^{* * *}$ \\
HA & $0.448^{* * *}$ & $0.335^{* * *}$ & $0.592^{* * *}$ & $0.532^{* * *}$ & $0.548^{* * *}$ & $0.656^{* * *}$ & 1 \\
BH & $0.351^{* * *}$ & $0.311^{* * *}$ & $0.442^{* * *}$ & $0.422^{* * *}$ & $0.379^{* * *}$ & $0.488^{* * *}$ & 0.51 \\
\hline
\end{tabular}




\subsection{Structural Equation Model}

LISRAL 9.2 was used to conduct path analysis of the hypothesis model of this study, the model's Chi-square $=412.30 ; \mathrm{df}=133$; Chi-square $/ 190=3.10 ; \mathrm{RMSEA}=0.074$; and $p$-value $=0.0000$. The model's goodness of fit was NFI $=0.902 ; \mathrm{NNFI}=0.911 ; \mathrm{CFI}=0.931$; and GFI=0.901, which were considered satisfactory [52-54]. The results obtained are as shown in Figure 2 below.

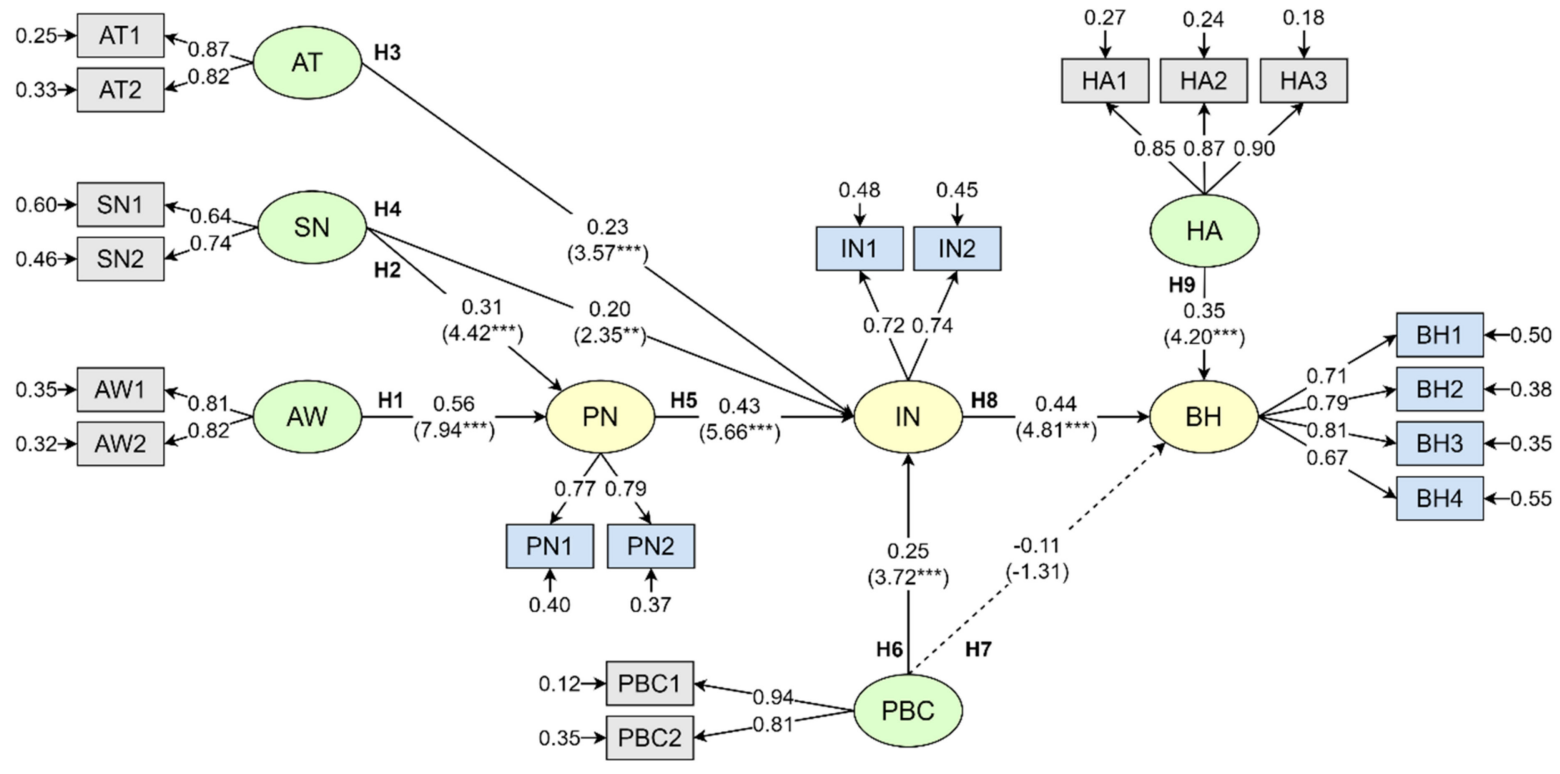

Chi-Square $=412.30, \mathrm{df}=133, \mathrm{P}$-value $=0.00000, \mathrm{RMSEA}=0.074$

Figure 2. Path analysis diagram of this study $t$-value ( $p$-value): $>1.96\left(p<0.05^{*}\right),>2.56\left(p<0.01^{* *}\right)>3.29\left(p<0.001^{* * *}\right)$.

The structural equation model has included the measurement model and the path model. The former was the result of its confirmatory factor analysis. Figure 2 presented the parameter result of the structural equation measurement model of this study. The parameter $\lambda$ was the factor loading and the acceptance standard is 0.4 [55]. As shown in Figure 2, parameter $\lambda$ of the awareness (AW) variable showed that $\mathrm{AW} 1=0.81^{* * *}$; AW2 $=0.82^{* * *}$. Parameter $\lambda$ of the personal norms $(\mathrm{PN})$ variable indicated that $\mathrm{PN} 1=0.77^{* * *} ; \mathrm{PN} 2=0.79^{* * *}$. Parameter $\lambda$ of the social norms (SN) variable suggested that $\mathrm{SN} 1=0.64^{* * *} ; \mathrm{SN} 2=0.74^{* * *}$. Parameter $\lambda$ of the perceived behavioral control (PBC) variable revealed that PBC1 $=0.94{ }^{* * *}$; $\mathrm{PBC} 2=0.81^{* * *}$. As for the recycling intentions (IN) variable, parameter $\lambda$ was IN1 $=0.72 * *$; IN2 $=0.74^{* * *}$. Parameter $\lambda$ of the recycling habits $(\mathrm{HA})$ variable indicated that HA1 $=0.85$ $* * *$ HA2 $=0.87^{* * *}$ HA3 $=0.90^{* * *}$. For the attitude (AT) variable, parameter $\lambda$ was AT1 $=0.87^{* * *} ;$ AT2 $=0.82^{* * *}$. Parameter $\lambda$ of the recycling behavior $(\mathrm{BH})$ variable showed that $\mathrm{BH} 1=0.71^{* * *} ; \mathrm{BH} 2=0.79^{* * *} ; \mathrm{BH} 3=0.81^{* * *} ; \mathrm{BH} 4=0.67^{* * *}$. The factor loading of all observed variables and latent variables was greater than 0.4 . as follow.

The findings of the path analysis for the respective hypotheses were briefly outlined

Hypothesis 1 (H1). Awareness has a positive impact on personal norms towards recycling behaviors (supported, path coefficient $\beta$-value of 0.56 and $t$-value of 7.94, which was statistically significant).

Hypothesis 2 (H2). Social norms have a positive impact on personal norms towards recycling behaviors (supported, path coefficient $\beta$-value of 0.31 and $t$-value of 4.42 , which was statistically significant). 
Hypothesis 3 (H3). Attitudes have a positive impact on recycling intentions (supported, path coefficient $\beta$-value of 0.23 and $t$-value of 3.57 , which was statistically significant).

Hypothesis 4 (H4). Social norms have a positive impact on recycling intentions (supported, path coefficient $\beta$-value of 0.20 and $t$-value of 2.35 , which was statistically significant).

Hypothesis 5 (H5). Personal norms have a positive impact on recycling intentions (supported, path coefficient $\beta$-value of 0.43 and $t$-value of 5.66 , which was statistically significant).

Hypothesis 6 (H6). Perceived behavioral control has a positive impact on recycling intentions (supported, path coefficient $\beta$-value of 0.25 and $t$-value of 3.72 , which was statistically significant).

Hypothesis 7 (H7). Perceived behavioral control has a positive impact on recycling behaviors (unsupported, path coefficient $\beta$-value of -0.11 and $t$-value of -1.31 , which was not statistically significant).

Hypothesis 8 (H8). Recycling intentions have a positive impact on recycling behaviors (supported, path coefficient $\beta$-value of 0.44 and $t$-value of 4.81 , which was statistically significant).

Hypothesis 9 (H9). Recycling habits have a positive effect on recycling behaviors (supported, path coefficient $\beta$-value of 0.35 and $t$-value of 4.20 , which was statistically significant).

A summary of the direct effects between the eight variables is presented in Table 10. Findings revealed that there were eight direct relationships between the variables identified as follow: (1) awareness (AW) on personal norms (PN) $\left(0.558^{* * *}, p<0.001^{* * *}\right)$; (2) personal norms (PN) on recycling intentions (IN) $\left(0.428^{* * *}, p<0.001^{* * *}\right)$; (3) social norms (SN) on personal norms (PN) $\left(0.306^{* * *}, p<0.001^{* * *}\right)$; (4) social norms (SN) on recycling intentions (IN) $\left(0.199^{* *}, p<0.01^{* *}\right)$; (5) perceived behavioral control (PBC) on recycling intentions (IN) $\left(0.247^{* * *}, p<0.001^{* * *}\right)$; (6) recycling intentions (IN) on recycling behaviors $(\mathrm{BH})\left(0.435^{* * *}\right.$, $\left.p<0.001^{* * *}\right)$; $(7)$ recycling habits (HA) on recycling behaviors (BH) $\left(0.354^{* * *}, p<0.001^{* * *}\right)$; and (8) attitudes (AT) on recycling intentions (IN) $\left(0.226^{* * *}, p<0.001^{* * *}\right)$.

Table 10. Statistics of direct effects.

\begin{tabular}{ccccccccc}
\hline & AW & PN & SN & PBC & IN & HA & AT & BH \\
\hline AW & & & & & & & & \\
PN & $0.558^{* * *}$ & & $0.306^{* * *}$ & & & & \\
SN & & & & & & & $0.226^{* * *}$ \\
PBC & & $0.428^{* * *}$ & $0.199^{* *}$ & $0.247^{* * * *}$ & & & \\
IN & & & & & & & \\
HA & & & & -0.112 & $0.435^{* * *}$ & $0.354^{* * *}$ & \\
AT & & & & & & & \\
BH & & & & & & & \\
\hline
\end{tabular}

$t$-value $(p$-value $)>1.96\left(p<0.05^{*}\right),>2.56\left(p<0.01^{* *}\right),>3.29\left(p<0.001^{* * *}\right)$.

\section{Discussions and Implications}

\subsection{Discussion of Findings}

Based on the earlier proposed research framework, this study aimed to gain further insights into the effects of awareness, social norms, personal norms, perceived behavioral control, attitudes, recycling behavior intentions, and recycling habits on the recycling behaviors of Taipei City residents. Although many studies have examined environmental behaviors (including recycling behaviors) with grounded theories (e.g., theory of planned behaviors, norm activation model), there still existed a general lack of investigation on other important variables such as habits, behavioral intentions, and situational circumstances. This study has adopted the comprehensive action determination model, which incorporated 
the abovementioned variables (that some grounded theories have not considered) in order to provide a more in-depth understanding about recycling behaviors. Results revealed that eight $(\mathrm{H} 1, \mathrm{H} 2, \mathrm{H} 3, \mathrm{H} 4, \mathrm{H} 5, \mathrm{H} 6, \mathrm{H} 8$, and $\mathrm{H} 9)$ out of the nine hypotheses developed for this study were supported and accepted, indicating positive direct relationships. The three key predictors of personal norms were awareness of consequences, ascription of responsibility, and awareness of needs. The perception scale of this study has been divided into awareness of consequences, ascription of responsibility, and awareness of needs. AW1 and AW2 had the highest goodness of fit with the model that positively affected personal norms, and AW1 and AW2 corresponded to the ascription of responsibility and it could therefore positively affect personal norms. This was evident from the results that the direct effect of the ascription of responsibility on personal norms was 0.558 , and this aligned with other studies [11,16,20].

When people act they often make choices based on the ideas of others in addition to considering their own circumstances. External information puts pressure on people, and normative pressure tends to guide the direction of decision-making and encourage actions that conform to external norms. Findings in this study indicated that the direct effect of social norms on personal norms was $0.31^{* * *}$, and this was consistent with prior studies $[20,21,30]$.

Attitudes are a function of belief, which refers to the preference of an individual's behaviors and attitudes toward things. When an individual has adopted a positive attitude to a certain behavior, it prompts him/her to engage in the behavior. On the contrary, if an individual has adopted a negative attitude to a certain behavior, that prompts him/her not to engage in the behavior. According to the findings, the direct effect of attitudes on recycling intentions was $0.23^{* * *}$, and this was supported by previous studies [31,39,41,56,57].

The direct effect of social norms on recycling intentions was 0.199 . This result was consistent with other previous studies $[20,29,33,56]$.

Taking actions based on moral obligations has been a powerful motivation for execution. Personal norms have been regarded as an important factor in influencing environmentrelated behaviors. When encountering a situation that needed to be dealt with, people's personal norms and conscience would be activated and affect their behaviors. Findings indicated that personal norm had a direct effect of $0.428^{* * *}$ on recycling intentions, and this aligned with other studies [21,35,37].

Findings revealed that the direct effect of perceived behavioral control on recycling intention was $0.247^{* * *}$. This result was supported by other prior studies $[21,37,45,57]$.

Perceived behavior control refers to the difficulty of an individual in engaging in certain behaviors and is a condition that the individual needs to consider before performing behaviors. It is also important to recognize the factors that one can control. Perceived behavioral control could be categorized into external control and internal control. Internal control is individual behavior, such as personal shortcomings, skills, abilities, or emotions. Whereas external control factors include information, opportunities, etc. Based on the scales developed by Ofstad et al. [25], and Tonglet et al. [45], the results in this study showed that the direct effect of perceived behavior control on recycling behaviors was -0.112 . Kaiser and Gutscher [40] used the theory of planned behavior to explore the recycling behaviors of Swiss residents and found that when predicting people's performance at a specific location, time, and situation, the behavior could be accurately and consistently predicted. In other words, perceived behavior control was an accurate representation of actual control and situational influence. It was also alike to use perceived behavior control to predict recycling behaviors. In this study, perceived behavioral control was no longer a key factor in predicting recycling behaviors, because the waste management and recycling methods adopted by Taipei City and apartment buildings were slightly different. Residents might take waste for recycling and wait for the recycling truck at a designated point in time or to the designated room in the apartment building. This result was consistent with a study by Kaiser and Gutscher [40] that suggested perceived behavioral control was not critical to the prediction of recycling behaviors. 
Behavioral intentions refer to the degree and tendency of an individual to engage in a specific behavior, which could be transformed into a predictable and interpretable actual behavior of an individual through measurement. In this study, recycling intentions could be regarded as the degree and tendency of individuals to engage in recycling behaviors and how much effort they were willing to make for recycling, used to explain the actual individual recycling behaviors. The direct effect of recycling intentions on recycling behaviors was $0.435^{* * *}$, and this was consistent with other previous studies $[35,39,45]$.

Verplanken and Aarts [43] mentioned that if a behavior has become habitual, the influence of psychological variables such as personal norms or intentions on the behavior would be weakened, and then the behavior would become involuntary. Habit is defined as a specific situational learning that has become an automated process and leads to practical goals or results. The development of habit is dependent on the catalysts and prompt reflection of the goal of behavior. Findings in this study showed that recycling habits had a positive impact on recycling behaviors. The direct effect of recycling habits on recycling behaviors was $0.354^{* * *}$, which was a moderate correlation, indicating that the respondent became used to recycling behaviors, thereby the influence of the recycling intentions and personal norms were weakened, and this aligned with the argument described by Verplanken and Aarts [43], and other studies [5-7].

\subsection{Theoretical and Practical Implications}

Numerous studies in the past have predominantly used the normative activation model and the theory of planned behavior to investigate pro-environmental behaviors, but there has been criticism of these models regarding their lack of inclusion of psychological variables which are essential in understanding human behavior patterns. While the comprehensive action determination model [18] has been developed to overcome this limitation, there have been very few studies conducted to provide further insights on the applicability of this model to a variety of situations and behaviors. This study has contributed to the extant literature about environmental behaviors, specifically with the use of the comprehensive action determination model. The findings of this study have provided further insights about the comprehensive action determination model, and verified the relationships between the variables associated with the recycling behaviors of Taipei City residents. It is evident in this study that psychological variables (e.g., recycling intentions, perceived behavioral control, personal norms, social norms, and recycling habits) are important influencing factors towards recycling behaviors. Furthermore, the path analysis results on the recycling behaviors of the Taipei City residents have further enhanced our understanding and knowledge about the comprehensive action determination model which is otherwise limited in previous studies $[18,25]$.

In terms of practical implications, it is suggested that government authorities and agencies actively develop and promote campaigns on a regular basis to create recycling awareness so that people are constantly aware and reminded of the need to exhibit recycling behaviors. Educational activities could also be facilitated through the support of schools, public and private organizations, and local residential communities, in order to broaden individual's relevant knowledge and recognition for the need to recycle. The designated garbage and resource recovery pick-up points could also be further expanded to include other locations and additional time schedules, to support the government's message about the significance of recycling and to help develop recycling habits through daily routines.

\section{Conclusions, Limitations, and Future Research}

In conclusion, this study has used the comprehensive action determination model to investigate the impact of awareness, social norms, personal norms, perceived behavioral control, attitudes, recycling behavior intentions, and recycling habits on the recycling behaviors of Taipei City residents. Findings have supported all hypotheses developed for this study, except for one that posited perceived behavioral control as having a positive impact on recycling behaviors. The findings have contributed to the extant literature about envi- 
ronmental behaviors, specifically with the use of the comprehensive action determination model which included variables that other grounded theories have neglected.

A limitation of this study is the use of a self-report survey which may be subjected to response bias and a lack of introspective ability by the respondents. The findings in this study are only applicable to Taipei City and cannot be generalized to the population at large in Taiwan or in other parts of the world or contexts that are different to the settings outlined in this research. In order to seek generalization of the findings, a much more representative sampling of the population is required. In addition, a similar study can be conducted in other countries so that a cross comparison between countries can be made to determine any similarities and differences.

Author Contributions: W.-T.F., Y.-T.C., M.-H.H, and. C.-W.H. conceived and designed the experiments; Y.-T.C. and. C.-W.H. performed the experiments; W.-T.F., Y.-T.C., B.-Y.C., R.-J.C., and E.N. analyzed the data; W.-T. F and Y.-T.C. contributed analysis tools; W.-T.F., Y.-T.C., M.-H.H., B.-Y.C., R.-J.C., and E.N. wrote the paper. All authors have read and agreed to the published version of the manuscript.

Funding: This research was supported by grants from the Ministry of Science and Technology (109-2511-H-003 -031 to W.-T. Fang). This article was also subsidized by the National Taiwan Normal University (NTNU), Taiwan.

Institutional Review Board Statement: The study was conducted according to the guidelines of the Declaration of Helsinki, and approved by the Research Ethics Committee, National Taiwan Normal University (REC Number: 201912HS001, Approval Date: 3 April 2020).

Informed Consent Statement: Informed consent was obtained from all subjects involved in the study.

Data Availability Statement: Data sharing not applicable.

Acknowledgments: We thank the members of the Graduate Institute of Environmental Education, National Taiwan Normal University (NTNU), for their contributions to the manuscript. Useful suggestions from anonymous reviewers were incorporated into the manuscript.

Conflicts of Interest: The authors declare no conflict of interest.

\section{References}

1. Carfora, V.; Caso, D.; Sparks, P.; Conner, M. Moderating effects of pro-environmental self-identity on pro-environmental intentions and behaviour: A multi-behaviour study. J. Environ. Psychol. 2017, 53, 92-99. [CrossRef]

2. Greaves, M.; Zibarras, L.D.; Stride, C. Using the theory of planned behavior to explore environmental behavioral intentions in the workplace. J. Environ. Psychol. 2013, 34, 109-120. [CrossRef]

3. Ajzen, I. The theory of planned behavior. Organ. Behav. Hum. Decis. Process. 1991, 50, 179-211. [CrossRef]

4. Ajzen, I. From intentions to actions: A theory of planned behavior. In Action Control: From Cognition to Behavior; Kuhl, J., Beckmann, J., Eds.; Springer: Berlin/Heidelberg, Germany, 1985; pp. 11-39.

5. Cheung, S.F.; Chan, D.K.S.; Wong, Z.S.Y. Reexamining the Theory of Planned Behavior in Understanding Wastepaper Recycling. Environ. Behav. 1999, 31, 587-612. [CrossRef]

6. Ittiravivongs, A. Recycling as habitual behavior: The impact of habit on household waste recycling behavior in Thailand. Asian Soc. Sci. 2012, 8, 74. [CrossRef]

7. Carrus, G.; Passafaro, P.; Bonnes, M. Emotions, habits and rational choices in ecological behaviours: The case of recycling and use of public transportation. J. Environ. Psychol. 2008, 28, 51-62. [CrossRef]

8. Macovei, O.-I. Applying the theory of planned behavior in predicting proenvironmental behaviour: The case of energy conservation. Acta Univ. Danub. Acon. 2015, 11,15-32.

9. Ajzen, I. Consumer attitudes and behavior: The theory of planned behavior applied to food consumption decisions. Ital. Rev. Agric. Econ. 2015, 70, 121-138.

10. Yadav, R.; Pathak, G.S. Young consumers' intention towards buying green products in a developing nation: Extending the theory of planned behavior. J. Clean. Prod. 2016, 135, 732-739. [CrossRef]

11. Schwartz, S.H. Normative influences on altruism. In Advances in Experimental Social Psychology; Leonard, B., Ed.; Academic Press: Cambridge, MA, USA, 1977; Volume 10, pp. 221-279.

12. Thøgersen, J. Norms for environmentally responsible behaviour: An extended taxonomy. J. Environ. Psychol. 2006, 26, $247-261$. [CrossRef] 
13. De Groot, J.I.M.; Steg, L. Morality and Prosocial Behavior: The Role of Awareness, Responsibility, and Norms in the Norm Activation Model. J. Soc. Psychol. 2009, 149, 425-449. [CrossRef] [PubMed]

14. Mainieri, T.; Barnett, E.G.; Valdero, T.R.; Unipan, J.B.; Oskamp, S. Green Buying: The Influence of Environmental Concern on Consumer Behavior. J. Soc. Psychol. 1997, 137, 189-204. [CrossRef]

15. Mehdizadeh, M.; Zavareh, M.F.; Nordfjaern, T. Mono- and multimodal green transport use on university trips during winter and summer: Hybrid choice models on the norm-activation theory. Transp. Res. Part A Policy Pract. 2019, 130, 317-332. [CrossRef]

16. Eriksson, L.; Garvill, J.; Nordlund, A.M. Acceptability of travel demand management measures: The importance of problem awareness, personal norm, freedom, and fairness. J. Environ. Psychol. 2006, 26, 15-26. [CrossRef]

17. Lopes, J.R.N.; Kalid, R.d.A.; Rodríguez, J.L.M.; Ávila Filho, S. A new model for assessing industrial worker behavior regarding energy saving considering the theory of planned behavior, norm activation model and human reliability. Resour. Conserv. Recycl. 2019, 145, 268-278. [CrossRef]

18. Klöckner, C.A.; Blöbaum, A. A comprehensive action determination model: Toward a broader understanding of ecological behaviour using the example of travel mode choice. J. Environ. Psychol. 2010, 30, 574-586. [CrossRef]

19. Taipei City Government. Department of Environmental Protection 2016 Annual Report; Taipei City Government: Taipei City, Taiwan, 2016.

20. Hopper, J.R.; Nielsen, J.M. Recycling as Altruistic Behavior: Normative and Behavioral Strategies to Expand Participation in a Community Recycling Program. Environ. Behav. 1991, 23, 195-220. [CrossRef]

21. Bamberg, S.; Hunecke, M.; Blöbaum, A. Social context, personal norms and the use of public transportation: Two field studies. J. Environ. Psychol. 2007, 27, 190-203. [CrossRef]

22. Cialdini, R.B.; Reno, R.R.; Kallgren, C.A. A focus theory of normative conduct: Recycling the concept of norms to reduce littering in public places. J. Personal. Soc. Psychol. 1990, 58, 1015. [CrossRef]

23. Stok, F.M. Eating by the Norm: The Influence of Social Norms on Young People's Eating Behavior; Utrecht University: Utrecht, The Netherlands, 2014.

24. Klöckner, C.A.; Oppedal, I.O. General vs. domain specific recycling behaviour-Applying a multilevel comprehensive action determination model to recycling in Norwegian student homes. Resour. Conserv. Recycl. 2011, 55, 463-471. [CrossRef]

25. Ofstad, S.P.; Tobolova, M.; Nayum, A.; Klöckner, C.A. Understanding the Mechanisms behind Changing People's Recycling Behavior at Work by Applying a Comprehensive Action Determination Model. Sustainability 2017, 9, 204. [CrossRef]

26. Fishbein, M.; Ajzen, I. Belief, Attitude, Intention, and Behavior: An Introduction to Theory and Research; Addison-Wesley: Reading, MA, USA, 1977.

27. Kurisu, K. Pro-Environmental Behaviors; Springer: Berlin/Heidelberg, Germany, 2015.

28. Armitage, C.J.; Conner, M. Efficacy of the Theory of Planned Behaviour: A meta-analytic review. Br. J. Soc. Psychol. 2001, 40, 471-499. [CrossRef] [PubMed]

29. Harland, P.; Staats, H.; Wilke, H.A.M. Explaining Proenvironmental Intention and Behavior by Personal Norms and the Theory of Planned Behavior. J. Appl. Soc. Psychol. 1999, 29, 2505-2528. [CrossRef]

30. Doran, R.; Larsen, S. The Relative Importance of Social and Personal Norms in Explaining Intentions to Choose Eco-Friendly Travel Options. Int. J. Tour. Res. 2016, 18, 159-166. [CrossRef]

31. Nigbur, D.; Lyons, E.; Uzzell, D. Attitudes, norms, identity and environmental behaviour: Using an expanded theory of planned behaviour to predict participation in a kerbside recycling programme. Br. J. Soc. Psychol. 2010, 49, 259-284. [CrossRef]

32. Park, J.; Ha, S. Understanding Consumer Recycling Behavior: Combining the Theory of Planned Behavior and the Norm Activation Model. Fam. Consum. Sci. Res. J. 2014, 42, 278-291. [CrossRef]

33. Bratt, C. The Impact of Norms and Assumed Consequences on Recycling Behavior. Environ. Behav. 1999, 31, 630-656. [CrossRef]

34. Chan, L.; Bishop, B. A moral basis for recycling: Extending the theory of planned behaviour. J. Environ. Psychol. 2013, 36, 96-102. [CrossRef]

35. Ioannou, T.; Zampetakis, L.A.; Lasaridi, K. Psychological determinants of household recycling intention in the context of the Theory of Planned Behaviour. Fresenius Environ. Bull. 2013, 22, 2035-2041.

36. Kim, S.H.; Seock, Y.K. The roles of values and social norm on personal norms and pro-environmentally friendly apparel product purchasing behavior: The mediating role of personal norms. J. Retail. Consum. Serv. 2019, 51, 83-90. [CrossRef]

37. Bamberg, S.; Möser, G. Twenty years after Hines, Hungerford, and Tomera: A new meta-analysis of psycho-social determinants of pro-environmental behaviour. J. Environ. Psychol. 2007, 27, 14-25. [CrossRef]

38. Notani, A.S. Moderators of Perceived Behavioral Control's Predictiveness in the Theory of Planned Behavior: A Meta-Analysis. J. Consum. Psychol. 1998, 7, 247-271. [CrossRef]

39. Mahmud, S.N.D.; Osman, K. The determinants of recycling intention behavior among the Malaysian school students: An application of theory of planned behaviour. Procedia Soc. Behav. Sci. 2010, 9, 119-124. [CrossRef]

40. Kaiser, F.G.; Gutscher, H. The Proposition of a General Version of the Theory of Planned Behavior: Predicting Ecological Behavior1. J. Appl. Soc. Psychol. 2003, 33, 586-603. [CrossRef]

41. Taylor, S.; Todd, P. An Integrated Model of Waste Management Behavior: A Test of Household Recycling and Composting Intentions. Environ. Behav. 1995, 27, 603-630. [CrossRef]

42. Perugini, M.; Bagozzi, R.P. The role of desires and anticipated emotions in goal-directed behaviours: Broadening and deepening the theory of planned behaviour. Br. J. Soc. Psychol. 2001, 40, 79-98. [CrossRef] 
43. Verplanken, B.; Aarts, H. Habit, Attitude, and Planned Behaviour: Is Habit an Empty Construct or an Interesting Case of Goal-directed Automaticity? Eur. Rev. Soc. Psychol. 1999, 10, 101-134. [CrossRef]

44. Verplanken, B.; Orbell, S. Reflections on Past Behavior: A Self-Report Index of Habit Strength1. J. Appl. Soc. Psychol. 2003, 33, 1313-1330. [CrossRef]

45. Tonglet, M.; Phillips, P.S.; Read, A.D. Using the Theory of Planned Behaviour to investigate the determinants of recycling behaviour: A case study from Brixworth, UK. Resour. Conserv. Recycl. 2004, 41, 191-214. [CrossRef]

46. Lodico, M.G.; Spaulding, D.T.; Voegtle, K.H. Methods in Educational Research: From Theory to Practice; John Wiley \& Sons: Hoboken, NJ, USA, 2010; Volume 28.

47. Roscoe, J.T. Fundamental Research Statistics for the Behavioral Sciences; Holt, Rinehart and Winston: New York, NY, USA, 1975.

48. Klöckner, C.A.; Matthies, E. Structural Modeling of Car Use on the Way to the University in Different Settings: Interplay of Norms, Habits, Situational Restraints, and Perceived Behavioral Control1. J. Appl. Soc. Psychol. 2009, 39, 1807-1834. [CrossRef]

49. Ramayah, T.; Lee, J.W.C.; Lim, S. Sustaining the environment through recycling: An empirical study. J. Environ. Manag. 2012, 102, 141-147. [CrossRef] [PubMed]

50. Minton, A.P.; Rose, R.L. The Effects of Environmental Concern on Environmentally Friendly Consumer Behavior: An Exploratory Study. J. Bus. Res. 1997, 40, 37-48. [CrossRef]

51. Taber, K.S. The use of Cronbach's alpha when developing and reporting research instruments in science education. Res. Sci. Educ. 2018, 48, 1273-1296. [CrossRef]

52. McDonald, R.P.; Ho, M.R. Principles and practice in reporting structural equation analysis. Psychol. Methods 2002, 7, 64-82. [CrossRef] [PubMed]

53. Hooper, D.; Coughlan, J.; Mullen, M.R. Structural equation modelling: Guidelines for determining model fit. Electron. J. Bus. Res. Methods 2008, 6, 53-59.

54. Bearden, W.O.; Sharma, S.; Teel, J.E. Sample size effects on chi square and other statistics used in evaluating causal models. J. Market. Res. 1982, 19, 425-430. [CrossRef]

55. Fornell, C.; Larcker, D.F. Evaluating structural equation models with unobservable variables and measurement error. J. Mark. Res. 1981, 18, 39-50. [CrossRef]

56. Nguyen, T.N.; Nguyen, H.V.; Lobo, A.; Dao, T.S. Encouraging Vietnamese Household Recycling Behavior: Insights and Implications. Sustainability 2017, 9, 179. [CrossRef]

57. Thi Thu Nguyen, H.; Hung, R.J.; Lee, C.H.; Thi Thu Nguyen, H. Determinants of residents' E-waste recycling behavioral intention: A case study from Vietnam. Sustainability 2019, 11, 164. [CrossRef] 